\title{
Effect of Maternal Body Mass Index in Relation to Embryo Quality and Clinical Outcomes in Couples underlying ICSI.
}

\author{
Ahmed S. Soliman (1), Shokry A. El Awady (2), Haitham M. Wahab ${ }^{(1)}$ \\ (1) Department of Obstetrics \& Gynecology, Faculty of Medicine, Al-Azhar University \\ (2) Department of Obstetrics \& Gynecology, the International Islamic Center for Population Studies \\ and Research, \\ Al-Azhar University
}

Corresponding author: Haitham M. Wahab; Mobile: 01019595567; Email: dr_haitham68@yahoo.com

\begin{abstract}
Background: The rising incidence of obesity coupled with its detrimental effects on fertility led to greater numbers of overweight and obese women utilizing assisted reproduction technologies (ART), such as in vitro fertilization (IVF) and intracytoplasmic sperm injection (ICSI).

Aim of the Work: To evaluate the impact of body mass index on embryo quality and clinical outcomes in couples underlying ICSI.

Patients and methods: a retrospective observational comparative study was conducted on 400 Women at ART Unit, International Islamic Centre for Population Studies and Research (IICPSR), Al-Azhar University. Data were recruited from the patient's files who did ICSI trial in IICPSR from December 2015 to December 2017, after exclusion of cycles in which the body mass index (BMI) was not recorded. After approval of the local ethics committee, all pregnant women were briefed about the nature of the study and informed consent was obtained from them before inclusion in the study.

Results: The duration of infertility was progressively higher as BMI increased. Basal luteinizing hormone, follicle-stimulating hormone, and estradiol levels were higher in group 2 than in group 1. Higher total doses of gonadotropin were required in group 2 to obtain equivalent ovarian response than in group 1. No significant difference was observed on ovarian response and embryonic parameters. Serum estradiol level on ovulation triggering day was significantly higher in group 2. Ovarian hyperstimulation and cycle outcome were not significantly different between both groups. Conclusion: Overweight and obesity appear to have independent adverse effects on ovarian response to stimulation and outcomes in women undergoing ICSI.
\end{abstract}

Keywords: Body Mass Index, Embryo Quality, Clinical Outcomes Couples underlying ICSI

\section{Introduction}

Obesity has become a worldwide epidemic, with approximately 1.6 billion adults being overweight and 400 million obese ${ }^{(\mathbf{1}, \mathbf{2})}$. The effects of obesity and overweight were studied in various diseases. It was known that obesity might cause diabetes, osteoarthritis, cardiovascular diseases, sleep apnea, breast and uterine cancers and other reproductive disorders in women ${ }^{(3)}$. Body mass index (BMI) has been widely used to assess the degree of obesity and overweight objectively and used as an indicator in many studies.

Women with a raised BMI are known to have a threefold greater risk of infertility due to disturbances in the hypothalamic-pituitary axis ,menstrual cycle ,anovulation ,psychological and social factors ${ }^{(4)}$.

In the United States, about $66.7 \%$ of women and $75 \%$ of men are overweight or obese; out of which, nearly $50 \%$ of the women are of reproductive age, and about $17 \%$ of their children are aged $2-19$ years ${ }^{(5)}$.

A raised $\mathrm{BMI}$ is also related with a high risk of reproductive complications in women such as menstrual dysfunction, anovulation, and infertility ${ }^{(6,7)}$. The women with a higher BMI also show a lower conception rate and higher abortion rate (AR), and they usually experience other reproductive complications ${ }^{(8)}$.

Infertility affects one in seven couples and a significant proportion of these cases are thought to be either directly or indirectly related to obesity. Obese women in the general population have a lower chance of conception within one year of stopping contraception compared with normal-weight women. The combination of infertility and obesity confers 
some real challenges about the short and long term management of these women ${ }^{(9)}$.

The mechanism through which obesity is thought to affect female reproductive function is complex. Adiposity increases peripheral aromatization of androgens to estrogens with a concurrent decrease in the hepatic synthesis of sex-hormone-bindingprotein (SHBG). This is associated with a hypersecretion of luteinizing hormone (LH) and an increase of androgen to estrogen ratio with a consequent overall altered endocrine environment leading to impaired folliculogenesis. The overall adiposity is further associated with changes related to inflammation, coagulation and fibrinolysis ${ }^{(10)}$, as well as insulin resistance and metabolic syndrome ${ }^{(11)}$.

Many studies found that woman who are obese need a higher dose of FSH for ovarian stimulation, have a higher risk of cycle cancellation and usually have a few collected oocytes ${ }^{(12)}$.

Obesity has a significant negative effect on Assisted Reproductive Technology (ART) outcomes. Patients with a BMI more than 30 have up to $68 \%$ lower odds of having a live birth following their first ART cycle compared to women with a BMI less than 30 (13).

\section{Aim of the Work}

To evaluate the impact of body mass index on embryo quality and clinical outcomes in couples underlying ICSI.

\section{Patients and methods}

\section{Type of the study:}

This is a retrospective observational comparative study to evaluate the impact of maternal body mass index on embryo quality and clinical outcomes in couples underlying ICSI by comparing clinical outcomes in overweight and obese women to those with normal range BMI.
This retrospective study was conducted on 400 Women at ART Unit, International Islamic Centre for Population Studies and Research (IICPSR), Al-Azhar University. Data were recruited from patient's files in IICPSR from December 2015 to December 2017, who had ICSI trial during this period after exclusion of cycles in which the body mass index (BMI) was not recorded.

After approval of the local ethics committee, all pregnant women were briefed about the nature of the study and informed consent was obtained from them before inclusion in the study.

\section{Inclusion Criteria:}

- Patient age between 19- 35 years

- $\quad$ BMI $>18$

- Type of infertility : 1 year

- Underwent long agonist protocol

- FSH on third day of menstrual cycle $<15 \mathrm{IU} / \mathrm{ml}$

\section{Exclusion Criteria:}

- $\quad$ Age $>35$ years

- $\quad$ FSH $>15 \mathrm{IU} / \mathrm{ml}$

- $\quad$ BMI $<18$

- Obliterated ( or distorted ) uterine cavity

- Impaired liver functions tests

- Impaired renal function tests

- Multiple fibroids; large fibroids or small fibroids distorting the uterine cavity.

Body Mass Index [BMI]: Height and Weight were retrieved from the database and the BMI was calculated using the following formula: Weight in $(\mathrm{kg}) /$ Height $\left(\mathrm{m}^{2}\right)$.

Patients were classified according to the BMI into two groups according to the World Health Organization (WHO) classification system for obesity ${ }^{\mathbf{( 1 4})}$ into: Group 1 (200 cases) Normal weight, BMI $18-24.9 \mathrm{~kg} / \mathrm{m} 2$. Group 2 (200 cases) Overweight and obese women, BMI $>25 \mathrm{~kg} / \mathrm{m} 2$.

So the following items in both groups are:

(1) Age, weight, height, BMI.

(2) Duration of infertility.

(3) Infertility workup results such as:

(a) Recent semen analysis.

(b) Recent hysterosalpingography. 
(c) Basal hormonal assay on third day of cycle [serum follicle-stimulating hormone

(FSH), luteinizing hormone (LH), estradiol (E2),prolactin, and thyroidstimulating

hormone].

(d) Baseline transvaginal ultrasound.

(4) Duration of stimulation.

(5) Total dose and number of ampoules of gonadotrophin administered.

(6) Ovarian response. The size and numbers of the follicles.

(7) The numbers and quality of oocyte retrieved.

(8) The numbers and quality of the embryo transferred (either fresh or cryopreserved).

(9) Pregnancy rate.

(10) Miscarriage and live birth rate.

\section{IVF Protocol:}

Patients were selected for ICSI cycle according to standard accepted indications. Patients underwent ovarian stimulation with a long agonist protocol.

Statistical analysis:
Recorded data were analyzed using the statistical package for social sciences, version 20.0 (SPSS Inc., Chicago, Illinois, USA). Quantitative data were expressed as mean \pm standard deviation (SD). Qualitative data were expressed as frequency and percentage.

\section{The following tests were done:}

- Independent-samples t-test of significance was used when comparing between two means.

- Chi-square $\left(\mathrm{x}^{2}\right)$ test of significance was used in order to compare proportions between qualitative parameters.

- The confidence interval was set to $95 \%$ and the margin of error accepted was set to $5 \%$. So, the p-value was considered significant as the following:

$*$ P-value $<0.05$ was considered significant.

$* *$ P-value $<0.001$ was considered as highly significant.

$\mathrm{P}$-value $>0.05$ was considered insignificant.

\section{Results}

The results of the present study are demonstrated in the following tables.

Table (1): Comparison between groups according to demographic data.

\begin{tabular}{|c|c|c|c|c|}
\hline Demographic data & $\begin{array}{l}\text { Group I (BMI 18- } \\
25)(n=200)\end{array}$ & $\begin{array}{lll}\begin{array}{l}\text { Group } \\
(n=200)\end{array} & \text { II } & (\text { BMI>25) } \\
\end{array}$ & t-test & $P$ value \\
\hline Age (years) & $29.28 \pm 5.56$ & $28.25 \pm 6.20$ & 1.474 & 0.170 \\
\hline Weight $(\mathrm{kg})$ & $58.95 \pm 5.89$ & $71.68 \pm 11.16$ & 12.155 & $<0.001 * *$ \\
\hline Height $(\mathrm{m})$ & $1.63 \pm 0.07$ & $1.61 \pm 0.06$ & 1.991 & 0.067 \\
\hline BMI [wt/(ht)^2] & & & & \\
\hline Mean \pm SD & $23.51 \pm 1.63$ & $29.16 \pm 3.83$ & \multirow{2}{*}{16.335} & \multirow{2}{*}{$<0.001 * *$} \\
\hline Range & $19.41-24.87$ & $25.78-42.19$ & & \\
\hline
\end{tabular}

$t$-Independent sample t-test;

p-value >0.05 NS; *p-value <0.05 $S$; **p-value <0.001 HS

This table shows statistically significant difference between groups according to weight and BMI.

Table (2): Comparison between groups according to duration of infertility (years).

\begin{tabular}{|l|l|l|l|l|}
\hline Duration of infertility (years) & $\begin{array}{l}\text { Group I (BMI 18- } \\
\text { 25) }(\mathbf{n = 2 0 0})\end{array}$ & $\begin{array}{l}\text { Group II (BMI>25) } \\
(\mathbf{n = 2 0 0})\end{array}$ & t-test & P value \\
\hline Mean \pm SD & $4.64 \pm 2.24$ & $5.15 \pm 2.49$ & 2.542 & $0.032 *$ \\
\hline
\end{tabular}

t-Independent sample t-test;

*p-value $<0.05 \mathrm{~S}$

This table shows statistically significant difference between groups according to duration of infertility which is longer in group 2 .

Table (3): Comparison between groups according to basal hormonal profile. 
Effect of Maternal Body Mass Index in Relation to Embryo Quality and Clinical Outcomes...

\begin{tabular}{|l|l|l|l|l|}
\hline Items & $\begin{array}{l}\text { Group I (BMI 18- } \\
\text { 25) }(\mathbf{n = 2 0 0})\end{array}$ & $\begin{array}{l}\text { Group II (BMI>25) } \\
(\mathbf{n = 2 0 0})\end{array}$ & t-test & P value \\
\hline FSH $(\mathrm{mIU} / \mathrm{l})$ & $6.62 \pm 1.78$ & $6.67 \pm 1.80$ & 0.252 & 0.711 \\
\hline LH $(\mathrm{mIU} / \mathrm{l})$ & $4.52 \pm 1.90$ & $5.04 \pm 1.12$ & 3.148 & $0.017^{*}$ \\
\hline PRL $(\mathrm{ng} / \mathrm{ml})$ & $15.12 \pm 3.35$ & $15.44 \pm 3.48$ & 0.957 & 0.400 \\
\hline Basal E2 (pg/ml) & $50.40 \pm 2.17$ & $39.27 \pm 6.49$ & 2.903 & $0.027^{*}$ \\
\hline
\end{tabular}

$t$-Independent sample t-test;

p-value $>0.05 \mathrm{NS}$; *p-value $<0.05 \mathrm{~S}$

This table shows statistically significant difference between groups according to basal hormonal profile, where LH is higher in group 2 while E2 is higher in group 1.

Table (4): Comparison between groups according to ovarian stimulation and ovarian response.

\begin{tabular}{|l|l|l|l|l|}
\hline Items & $\begin{array}{l}\text { Group I (BMI 18- } \\
\mathbf{2 5})(\mathbf{n = 2 0 0})\end{array}$ & $\begin{array}{l}\text { Group II (BMI>25) } \\
(\mathbf{n = 2 0 0})\end{array}$ & t-test & P value \\
\hline Number of ampoules & $35 \pm 12$ & $38 \pm 13$ & 2.346 & $0.039^{*}$ \\
\hline Duration of stimulation (days) & $12.99 \pm 4.42$ & $13.19 \pm 4.48$ & 0.725 & 0.503 \\
\hline Number of follicles (US) & $10 \pm 5$ & $9 \pm 4$ & 0.443 & 0.665 \\
\hline Endometrial thickness (mm) & $11.74 \pm 5.99$ & $11.62 \pm 5.91$ & 0.371 & 0.710 \\
\hline Level of E2 on trigger (pg/ml) & $2475.9 \pm 841.8$ & $2995.3 \pm 1018.3$ & 2.317 & $0.042^{*}$ \\
\hline
\end{tabular}

$t$-Independent sample t-test;

p-value $>0.05 \mathrm{NS} ;{ }^{*} p$-value $<0.05 \mathrm{~S}$

This table shows statistically significant difference between groups according to number of ampules and level of E2 on trigger where the number of ampoules and level of E2 are higher in group 2.

Table (5): Comparison between groups according to ovarian stimulation and oocyte.

\begin{tabular}{|l|l|l|l|l|}
\hline Ovarian stimulation and oocyte & $\begin{array}{l}\text { Group I (BMI 18- } \\
\text { 25) }(\mathbf{n = 2 0 0})\end{array}$ & $\begin{array}{l}\text { Group } \\
(\mathbf{B M I}>\mathbf{2 5}) \\
(\mathbf{n = 2 0 0})\end{array}$ & t-test & P value \\
\hline Number of oocytes collected & $7 \pm 3$ & $8 \pm 3$ & 1.777 & 0.098 \\
\hline Number of GV oocytes & $2 \pm 1$ & $1 \pm 1$ & 1.440 & 0.176 \\
\hline Number of metaphase 1 oocytes & $2 \pm 1$ & 2.256 & $0.037^{*}$ \\
\hline Number of metaphase 2 oocytes & $4 \pm 2$ & $4 \pm 2$ & 0.972 & 0.347 \\
\hline Number of transferred embryos & $2.82 \pm 1.27$ & $2.43 \pm 1.09$ & 3.839 & $<0.001^{* *}$ \\
\hline
\end{tabular}

$t$-Independent sample t-test;

p-value >0.05 NS; *p-value <0.05 S; **p-value <0.001 HS

This table shows statistically significant difference between groups according to number of metaphase 1 oocytes and number of transferred embryos being higher in group 1 .

Table (6): Comparison between groups according to embryo quality.

\begin{tabular}{|l|l|l|l|l|}
\hline Embryo quality & $\begin{array}{l}\text { Group I (BMI 18- } \\
\text { 25) }(\mathbf{n = 2 0 0})\end{array}$ & $\begin{array}{l}\text { Group II (BMI> 25) } \\
(\mathbf{n = 2 0 0})\end{array}$ & $\mathbf{x 2}$ & P value \\
\hline Grade A & $190(95 \%)$ & $166(83 \%)$ & 9.669 & $0.002 *$ \\
\hline Grade B & $56(28 \%)$ & $70(35 \%)$ & 1.221 & 0.268 \\
\hline
\end{tabular}

$X^{2}:$ Chi-square test

p-value $>0.05 \mathrm{NS}$; *p-value $<0.05 \mathrm{~S}$

This table shows statistically significant difference between groups according to embryo quality grade A appears better in group 1. 
Table (7): Comparison between groups according to outcome.

\begin{tabular}{|l|l|l|l|l|}
\hline Outcomes & $\begin{array}{l}\text { Group I (BMI 18- } \\
\text { 25) (n=200) }\end{array}$ & $\begin{array}{l}\text { Group II (BMI>25) } \\
(\mathbf{n = 2 0 0})\end{array}$ & x2 & P value \\
\hline $\begin{array}{l}\text { Pregnancy test } \\
\text { Negative } \\
\text { Positive }\end{array}$ & $\begin{array}{l}9(49.0 \%) \\
102(51.0 \%)\end{array}$ & $\begin{array}{l}124(62.0 \%) \\
76(38.0 \%)\end{array}$ & 4.685 & 0.056 \\
\hline $\begin{array}{l}\text { Aborted } \\
\text { Yes }\end{array}$ & $16(15.7 \%)$ & $20(26.3 \%)$ & & \\
No & $86(84.3 \%)$ & $56(73.7 \%)$ & 2.089 & 0.189 \\
\hline Live birth & $76(88.4 \%)$ & $50(89.3 \%)$ & & \\
Yes & $10(11.6 \%)$ & $6(10.7 \%)$ & 0.019 & 0.787 \\
No & & & \\
\hline
\end{tabular}

$x^{2}$ : Chi-square test; $p$-value $>0.05 \mathrm{NS}$

This table shows no statistically significant difference between groups according to outcome.

Table (8): Comparison between groups according to coasting and risk of ovarian hyperstimulation syndrome.

\begin{tabular}{|l|l|l|l|l|}
\hline $\begin{array}{l}\text { Coasting and risk of ovarian } \\
\text { hyperstimulation syndrome }\end{array}$ & $\begin{array}{l}\text { Group I (BMI 18- } \\
\mathbf{2 5})(\mathbf{n = 2 0 0})\end{array}$ & $\begin{array}{l}\text { Group II (BMI>25) } \\
(\mathbf{n = 2 0 0})\end{array}$ & x2 & P value \\
\hline $\begin{array}{l}\text { Coasting } \\
\text { Yes }\end{array}$ & $\begin{array}{l}55(27.5 \%) \\
145(72.5 \%)\end{array}$ & $\begin{array}{l}46(23.0 \%) \\
154(77.0 \%)\end{array}$ & 0.848 & 0.358 \\
No & $3(1.5 \%)$ & $7(3.5 \%)$ & & \\
\hline $\begin{array}{l}\text { Ovarian hyperstimulation syndrome } \\
\text { Yes }\end{array}$ & $197(98.5 \%)$ & $193(96.5 \%)$ & 0.923 & 0.337 \\
No & \\
\hline
\end{tabular}

$x^{2}$ : Chi-square test; $p$-value $>0.05 N S$

This table shows no statistically significant difference between groups according to coasting and risk of ovarian hyperstimulation syndrome.

\section{Discussion}

Worldwide, there is a dramatic increase in the prevalence of overweight and obesity in women of childbearing age. According to the World Health Organization (14), $46 \%$ of adult females in Egypt are obese. Between 1995 and 2005, the mean BMI of women of reproductive age in Egypt increased from $26.31 \mathrm{Kg} / \mathrm{m}^{2}$ to $28.52 \mathrm{Kg} / \mathrm{m}^{2}$. There was an overall trend towards greater obesity between 1995 and 2005 (15).

Obesity is related to reproductive performance and it is linked to a number of adverse reproductive outcomes including anovulation, PCOS, infertility and poor response to assisted conception treatments ${ }^{(16)}$. There is considerable evidence so far that obesity has an adverse effect on the outcome of IVF/ICSI cycles ${ }^{(\mathbf{1 2})}$.
The development and refinement of assisted reproductive technology (ART) over the last decades has coincided with a rapid increase in the prevalence of obesity among women of reproductive age ${ }^{(17)}$.

In this study, distribution of the studied sample according to BMI is categorized into two groups:

$1^{\text {st }}$ group: normal weight with BMI between 18.5 and $24.9 \mathrm{~kg} / \mathrm{m} 2$. (200 case) With their mean BMI $22.83 \pm 1.44$, (range 19.0324.92), and their age with mean $28.4 \pm 4.92$ years old.

$2^{\text {nd }}$ group : overweight and obese women $>25 \mathrm{~kg} / \mathrm{m} 2$ (200 case) With their mean BMI $28.31 \pm 3.39$ (range 25.56-44.30). and their age with mean $27.4 \pm 5.49$ years old, which shows significant difference between the two groups. P-value $(<0.001 * *)$.

In our study, the duration of infertility is progressively higher as BMI increases. As in group (1) it ranges from 1-17 years with mean duration 4.50, while in group (2) it range from 
1-25 with mean duration 5 years that shows significant difference $(\mathrm{P}$-value $=0.034 *)$. This agrees with a study by Bellver et al. ${ }^{(18)}$, Which shows a delay spontaneous conception in obese women, mainly caused by a higher risk of ovulatory infertility. However, women with regular ovarian cycles showes that the probability of pregnancy is reduced by $5 \%$ for every unit of BMI that exceeds $29 \mathrm{~kg} / \mathrm{m} 2$ with P-value 0.024*.

Overweight and obese infertile women in this study had lower basal serum FSH, LH and estradiol levels than normal weight women. This observation corresponds with previous studies that found impaired pulsatile secretion of pituitary gonadotrophin in obese women, leading to impaired folliculogenesis ${ }^{(19)}$. However, some authors disagree with our finding (20).

One of the most important observation drawn from our study is the need for higher doses of gonadotrophin for ovarian stimulation in overweight and obese women compared to normal weight women. This highlights a special state of "gonadotropin resistance ". This state led to longer periods of ovarian stimulation.

Most studies conducted in obese women undergoing IVF cycles agreed with us and reported the same observation ${ }^{(18)}$.

Raising several hypothesis. First, this increased dose requirement of gonadtrophin may be related to altered pharmacodynamic characteristics of drugs administered subcutaneous in obese women having increased subcutaneous fat thickness. Indeed, changes in absorption, metabolism, bioavailability and clearance had been reported in these women ${ }^{(21)}$.

In addition, our study noted that E2 levels in the HCG day are significantly higher in patients with higher BMI when compared to women with lower BMI. This corresponds with the study done by Rittenberg et al. ${ }^{(22)}$, but disagrees with the study done by Caillon et al. (21), Which aimed to provide assisted reproductive technology (ART) outcome rates per body mass index (BMI) category. In their study, higher BMI was associated with lower E2 levels in the day of HCG.

Several hypothesis have been raised, involving the relative hyperestrogenemia state or hyperinsulinemia and some pro- inflammatory cytokines (IL-6, TNF), which could create an unfavorable uterine environment for embryonic implantation. This low-grade inflammatory state had also been related to polycystic ovarian syndrome, independently of obesity ${ }^{(23)}$.

Our study shows that embryo quality and implantation rates are higher in normal weight than in obese women. This remains controversial in the literature, but conversely some authors did not find any effect of obesity upon implantation in IVF cycles ${ }^{(24)}$.

Our study found that oocyte number and quality are poorer in group 2 than in group 1 (although not significant). Number and quality of transferred embryo is higher in group 1 than in group $2(\mathrm{P}=0.003)$, and subsequently live birth rate tended to be poorer in group 2 than in group 1, (although not significant).

In an another retrospective study, done by Nichols et al. ${ }^{(25)}$, showed that the dose of gonadotrophin used, the number of oocytes retrieved, the number and quality of embryos transferred, and the miscarriage rate did not differ between the BMI groups. However, implantation and pregnancy rates were lower in the BMI $>25 \mathrm{~kg} / \mathrm{m} 2$ group than in the nornmal weight group ${ }^{(25)}$.

Contrarily, other studies reported a detrimental effect of increased female BMI on ovarian response to stimulation, lower number of oocytes retrieved, and lower number of embryos transferred ${ }^{(22)}$.

As many variables can impact IVF success rates, our observations on obesity must be interpreted in light of other factors, such as age, to establish treatment strategy.

The controversy over ART outcome in obese patients may be due to different cutoff values used to define obesity, inclusion of patients with different infertility etiologies, and/or varying focus of outcome measures ${ }^{(26)}$.

Our study found that obesity increases the duration of ovulation induction, increased the gonadotrophin dose required to achieve sufficient stimulation response, Increases the peak of estradiol levels on the day of HCG administration, decreased the number of mature follicles and number of oocytes retrieved. 
Obesity might have a negative impact on oocyte and embryo quality. So, fertilization, embryo transfer, implantation and pregnancy rates have been usually found to be low in obese patients in many studies. In addition, oocyte retrieval and embryo transfer procedures found to be difficult due to obesity itself. Finally, miscarriage rate found to be high and decrease pregnancy and live birth rates.

Female overweight and obesity appear to have deleterious effects on ovarian response to stimulation in women undergoing ICSI. Moreover, female obesity compromise ICSI outcomes.

\section{Conclusion:}

Obesity is a chronic disease requiring long-term management and support from respectful, sensitive and compassionate providers who believe that success is possible. Overweight and obesity appear to have independent adverse effects on ovarian response to stimulation and outcomes in women undergoing ICSI. overweight woman can be managed with continuous care that addresses the medical, nutritional and psychosocial aspects of this complex condition.

\section{References}

1. Prentice A (2006): The emerging epidemic of obesity in developing countries. Int. J. Epidemiol., 35: 93-99.

2. WHO (2006): Obesity and Overweight Geneva: World Health Organization. Available from: $<$ http://www.who.int/mediacentre/factshe ets/fs311/en/>.

3. Legato MJ (1997): Gender-specific aspects of obesity. Int J Fertil Womens Med., 42: 184-97.

4. van der Steeg JW, Steures P, Eijkemans MJ et al. (2008): Obesity affects spontaneous pregnancy chances in subfertile, ovulatory women. Hum Reprod., 23 (2): 324-328.

5. Pfeifer S, Fossum G, Pisarska M, Widra E, Sandlow J, Rosen M et al. (2015): Obesity and reproduction: A committee opinion. Fertil Steril., 104: 1116-26.

6. Clark AM, Ledger W, Galletly C, Tomlinson L, Blaney F, Wang X et al. (1995) Weight loss results in significant improvement in pregnancy and ovulation rates in anovulatory obese women. Hum Reprod., 10: 2705-12

7. Clark AM, Thornley B, Tomlinson L, Galletley C, Norman RJ (1998): Weight loss in obese infertile women results in improvement in reproductive outcome for all forms of fertility treatment. Hum Reprod., 13: 1502-5.

8. Bellver J, Pellicer A, García-Velasco JA, Ballesteros A, Remohí J, Meseguer M (2013): Obesity reduces uterine receptivity: Clinical experience from 9,587 first cycles of ovum donation with normal weight donors. Fertil Steril., 100: 1050-8.

9. Talmor A, Dunphy B (2015): Female obesity and infertility. Best Pract. Res. Clin. Obstet. Gynaecol., 29: 498-506.

10. Gosman GG, Katcher, HI, Legro RS (2006): Obesity and the role of gut and adipose hormones in female reproduction. Hum. Reprod. Update, 12: 585-601.

11. Levens ED, Skarulis MC (2008): Assessing the role of endometrial alteration amongobese patients undergoing assisted reproduction. Fertil. Steril., 89: 1606-1608.

12. Fedorcsak $P$, Dale PO, Storeng $R$ et al. (2004): Impact of overweight and underweight on assisted reproduction treatment. Hum Reprod., 19 (11): 25232528.

13. Moragianni VA, Jones SM, Ryley DA (2012): The effect of body mass index on the outcomes of first assisted reproductive technology cycles. Fertil Steril., 98: 102108

14. WHO (2015): Obesity and Overweight. Geneva: World Health Organization..

15. Austin AM, Hill AG, Fawzi WW (2013): Maternal obesity trends in Egypt 1995-2005. Maternal \& child nutrition, 9 (2): 167-79.

16. Metwally M, Cutting R, Tipton A, Skull J, Ledger WL, Li TC (2007): Effect of increased body mass index on oocyte and embryo quality in IVF patients. Reproductive biomedicine online, 15 (5): 532-8.

17. Flegal KM, Carroll MD, Ogden CL, Curtin LR (2010): Prevalence and trends 
Effect of Maternal Body Mass Index in Relation to Embryo Quality and Clinical Outcomes...

in obesity' among US adults, 1999-2008. JAMA., 303 (3): 235-241.

18. Bellver $\mathrm{J}$, Ayllon $\mathrm{Y}$, Ferrando $\mathrm{M}$ et al. (2010): Female obesity impairs in vitro fertilization outcome without affecting embryo quality. Fertil Steril., 93 (2): 447454.

19. De Pergola G, Maldera S, Tartagni M et al. (2012): Inhibitory effect of obesity on gonadotropin, estradiol, and inhibin B levels in fertile women. Obesity (Silver Spring), 14 (11): 1954-1960.

20. Dechaud H, Anahory T, Reyftmann L et al. (2006): Obesity does not adversely affect results in patients who are undergoing in vitro fertilization and embryo transfer. Eur J Obstet Gynecol Reprod Biol., 127 (1):88-93.

21. Caillon H, Freour T, Bach-Ngohou K et al. (2015): Effects of female increased body mass index on in vitro fertilization cycles outcome. Obes Res Clin Pract. , 9 (4): 382-388.
22. Rittenberg V, Seshadri S, Sunkara SK et al. (2011) : Effect of body mass index on IVF treatment outcome: an updated systematic review and meta-analysis. Reprod Biomed Online, 23 (4): 421-439.

23. Brewer CJ, Balen AH (2010): The adverse effects of obesity on conception and implantation. Reproduction, 140 (3): 347-364.

24. Haghighi $Z$, Rezaei $Z$, Es-Haghi Ashtiani S (2012): Effects of women's body mass index on in vitro fertilization success: a retrospective cohort study. Gynecol Endocrinol., 28 (7): 536-539.

25. Nichols JE, Crane MM, Higdon HL et al. (2013): Extremes of body mass index reduce in vitro fertilization pregnancy rates. Fertil Steril., 79 (3): 645-647.

26. Ozgun MT, Uludag S, Oner G et al. (2011): The influence of obesity on ICSI outcomes in women with polycystic ovary syndrome. J Obstet Gynaecol., 31 (3): 245-249. 